\title{
Impacts of shifts in spawning seasonality and size at maturation on the population growth of mantis shrimp in Tokyo Bay
}

\author{
Mifuyu Nakajima ${ }^{1,2,3, *}$, Keita Kodama $^{1}$, Toshihiro Horiguchi $^{1}$, Yoshinari Tanaka ${ }^{1}$, \\ Hiroaki Shiraishi ${ }^{1}$ \\ ${ }^{1}$ Research Center for Environmental Risk, National Institute for Environmental Studies, Japan, 16-2 Onogawa, Tsukuba-City, \\ Ibaraki 305-8506, Japan \\ ${ }^{2}$ Department of Zoology, University of Hawaii, 2538 McCarthy Mall, Edmondson 152 Honolulu, Hawaii 96822, USA
}

${ }^{3}$ Present address: Department of Biology, Stanford University, Stanford, California 94305, USA

\begin{abstract}
The spawning season of mantis shrimp Oratosquilla oratoria (Stomatopoda) in Tokyo Bay has changed from being unimodal (spring only) to bimodal (spring and summer).This shift in the pattern of spawning arose because reproductive maturation began to occur in smaller females, which presumably spawn in summer, and because the proportion of smaller mature females increased. Currently, recruitment appears to depend entirely on the summer cohort because of significantly lower juvenile survival in the spring cohort. In this study, we propose that the new summer spawning period and spawning by smaller-bodied individuals have supported the population. Our size- and agestructured mathematical model of $O$. oratoria population dynamics indicated that the number of eggs spawned in spring is lower than that in summer, and $98 \%$ of the annual recruitment is currently derived from summer spawning. The model also suggested that smaller-bodied spawners provided $84 \%$ of total recruitment and that if the proportion of smaller-bodied mature females had not increased, the population would have shown a larger decline than was observed. In reality, the stock size of $O$. oratoria has become extremely low, damaging the local fishery. Based on our model predictions, an efficient solution for population recovery is to reduce the mortality of small, unsalable individuals, which are currently fished and discarded.
\end{abstract}

KEY WORDS: Discarding $\cdot$ Life history - Oratosquilla oratoria $\cdot$ Recruitment $\cdot$ Seasonal survival • Settlement inhibition $\cdot$ Stomatopoda $\cdot$ Structured-population model

\section{INTRODUCTION}

The spawning season is often critical for population dynamics because larval survival and recruitment are strongly affected by physical and biotic factors that are highly variable among seasons (Lipcius 1985, Hutchings \& Myers 1993). Natural selection would be expected to favor a timing of spawning that avoids periods when conditions are unfavorable for spawned offspring (Hare \& Cowen 1993). However, in Tokyo Bay, Japan, the current juvenile survival rate for the earliest of 2 seasonal cohorts of mantis shrimp Oratosquilla oratoria appears to be significantly lower than that of the later cohort (Kodama et al. 2006a, 2009).

The life history of Oratosquilla oratoria includes a planktonic larval stage, with individuals settling 7 to 10 wk after spawning. After settlement in muddy bottoms (i.e. larvae metamorphose into juveniles and commence a benthic habit), individuals generally continue to molt and grow in body length, eventually becoming reproductively mature (Shimizu 2002). Mature females spawn all of their eggs at once (Ko- 
dama et al. 2004), generally every year (Shimizu 2002). The first seasonal peak of current spawning is primarily composed of females $\geq 10 \mathrm{~cm}$ in body length (from the base of the rostrum to the anterior edge of the median notch of the telson) and a few smaller females, whereas the second peak is dominated by smaller females (Kodama et al. 2004). Small, sexually mature females $(<10 \mathrm{~cm})$ were first observed in the 1980s (Ohtomi \& Shimizu 1988), and their proportion has since increased (Kodama et al. 2004). Changes in $O$. oratoria life history and the body-length structure of landings over the past few decades are summarized in Table 1. Kodama et al. (2006a, 2009) suggested that settlement failed only in the spring cohort in the 2000s; it thus appears to be a recent phenomenon. The early cohort spawned by larger females in the spring was able to support the population until at least the 1950s (Kubo et al. 1959). The causal mechanism of failed settlement remains unknown.

Oratosquilla oratoria have been fished by a bottomtrawl fishery in Tokyo Bay since the 19th century (Shimizu 2002). Individuals of salable size (Table 1) are selected from the catch on board and classified into 4 market sizes. Smaller individuals are discarded back into the ocean. The annual landings (i.e. caught and brought back to dry land) per unit effort (LPUE, number of landed ind. ship ${ }^{-1} \mathrm{~h}^{-1}$ ) have dropped to between 30 and $50 \%$ of the levels observed in the late 1980s (Shimizu 2002), and the proportion of the annual LPUE composed of large individuals has been decreasing since the 1970s (Fig. 1). O. oratoria appears to represent a single population, and no immigration from or emigration to populations outside the bay has been observed (Nakata 1986). To date, no data have indicated that the rates of somatic growth and reproductive development represent genetic differences between the small and large females or the spring and summer cohorts.

Reductions in the size at maturation have been reported for other crustaceans (e.g. Pollock 1995 and ref-

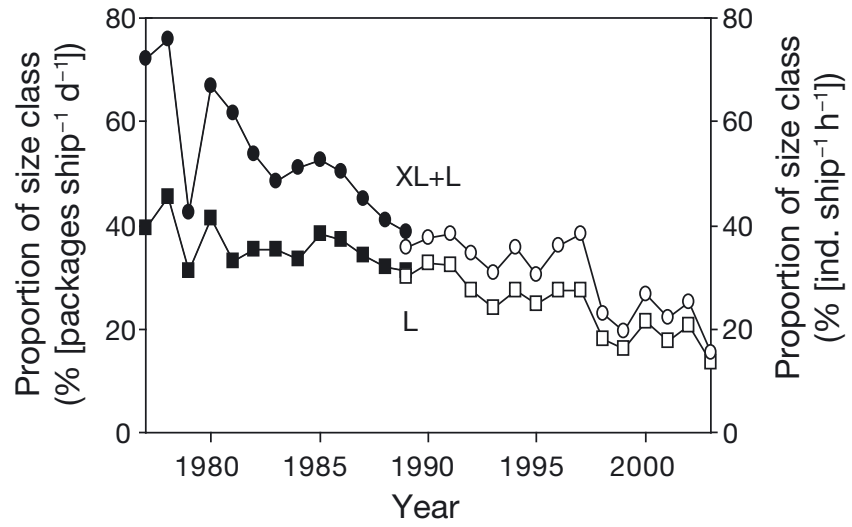

Fig. 1. Oratosquilla oratoria. Proportions of the 2 largest market size categories, i.e. XL (extra large, the largest category) and L (large, the second largest) in the total catch in units of the annual average landings per unit effort (LPUE) for the 1977 to 2003 period. Circles: XL + L, squares: L. Closed symbols: LPUE (number of packages ship ${ }^{-1} \mathrm{~d}^{-1}$ ) data for the 1977 to 1989 period (Ohtomi \& Shimizu 1996); open symbols: LPUE (ind. ship ${ }^{-1} \mathrm{~h}^{-1}$ ) data for the 1989 to 2003 period (Shimizu 2004)

erences therein). However, to our knowledge, no studies have reported changes in both size at maturation and spawning seasonality as observed in Oratosquilla oratoria, despite the fact that seasonality is related to the size of spawners. In this study, we discuss whether this shift in spawning pattern has effectively supported the population. Specifically, we first compared the current contributions of the newly appeared summer cohort and the traditional spring cohort, and of small spawners and large spawners, to the total population. For these assessments, we developed a size- and age-structured mathematical model. Second, to demonstrate the effect of the increased proportion of smaller-bodied spawners on population dynamics, we estimated recruitment and population growth rates assuming the proportion of mature females had not

Table 1. Oratosquilla oratoria. Observed population changes from 1955 to date

\begin{tabular}{|c|c|c|}
\hline Parameter & Old data & Current data \\
\hline Max. size landed & $17 \mathrm{~cm}$ in 1955 (Kubo et al. 1959) & $<15 \mathrm{~cm}$ at present (Kodama et al. 2009) \\
\hline Min. size landed & $11 \mathrm{~cm}$ in 1980s (Kitahara \& Maki 1997) & $10 \mathrm{~cm}$ in 2000s (Kodama et al. 2006b) \\
\hline Min. size at maturation & $\begin{array}{l}>10 \mathrm{~cm} \text { before 1960s (Kubo et al. 1959) } \\
8 \mathrm{~cm} \text { in } 1987 \text { (Ohtomi et al. 1988) }\end{array}$ & $7 \mathrm{~cm}$ in 2000s (Kodama et al. 2004) \\
\hline $50 \%$ size at maturation ${ }^{\mathrm{a}}$ & $10-12 \mathrm{~cm}$ in 1987 (Present study ${ }^{\mathrm{b}}$ ) & $7-8 \mathrm{~cm}$ in 2002 (Kodama et al. 2004) \\
\hline Age at first maturation & 1 yr before 1960s (Kubo et al. 1959) & before 1 yr in 2000s (Kodama et al. 2004) \\
\hline Spawning season & May-July before 1960s (Kubo et al. 1959) & $\begin{array}{l}\text { May-June and July-September from 1980s } \\
\text { to present (Kodama et al. 2004, Ohtomi \& } \\
\text { Shimizu 1988) }\end{array}$ \\
\hline
\end{tabular}


changed since the 1980s and compared these estimates to values from the actual population. In addition to these main objectives, our model also provided values of fishing mortalities for small and large individuals that could maintain the population. To examine how our parameter estimates influenced the model outputs, we conducted a sensitivity analysis.

\section{MODEL}

Equations. Our model describes the dynamics of 10 stages in an Oratosquilla oratoria population, divided by the spawning season, body length, and age: (1) spring-spawned young of the year (YOY), (2) summer-spawned YOY, (3) spring-spawned, small (body length $<10 \mathrm{~cm}$ ) 1 yr old adults, (4) spring-spawned, large (body length $\geq 10 \mathrm{~cm}$ ) 1 yr old adults, (5) summerspawned, small 1 yr old adults, (6) summer-spawned, large 1 yr old adults, (7) spring-spawned, small adults $\geq 2$ yr of age, (8) spring-spawned, large adults $\geq 2$ yr of age, (9) summer-spawned small adults $\geq 2$ yr of age, and (10) summer-spawned, large adults $\geq 2$ yr of age. We expressed the number of individuals at each stage in year $t$ as $N_{s p r 0, t}, N_{\text {sum } 0, t}, N_{\text {sprS1,t }}, N_{\text {sprL1,t }}, N_{\text {sum } S 1, t}$, $N_{\text {sumL1,t }}, N_{\text {sprS2+,t }}, N_{\text {sprL2+,t }}, N_{\text {sumS2+,t }}$, and $N_{\text {sumL2+,t }}$, respectively (parameters are also listed in Table 2). We separated the adult stages by body length because they differ in the number of eggs produced, maturation rates, and whether they are discarded or landed. Among the individuals caught by fishing, all large individuals are landed, whereas small individuals are discarded in our model. Individuals aged 1 and older are separated because they have different probabilities of growing to a larger size. The number of individuals was counted annually on 31 December. Fishery occurs throughout the year. For simplicity, we assumed that spawning in spring and summer occur discretely in May and August, respectively. The annual life-stage transitions and life history assumed in the model are summarized in Fig. 2. The parameters and their estimated values are summarized in Table 2 . The oldest observed individuals were estimated as $4 \mathrm{yr}$ old (Kodama et al. 2005).

The number of individuals that spawned in season $i$ ( $i=$ sum, spr; i.e. summer, spring) and at the oldest stage of small sizes in year $t+1$ is calculated from the number of younger individuals in year $t$ as

$$
N_{i S 2+, t+1}=\left[N_{i S 1, t}\left(1-G_{i 1}\right)+N_{i S 2+, t}\left(1-G_{i 2+}\right)\right] E_{D} S_{A}
$$

where $S_{A}$ is the annual intrinsic survivability of adults, and $E_{D}$ indicates the annual survivability against fishing for discarded individuals, i.e. (total survivability against fishing)-(annual survivability against landing, $\left.E_{L}\right) . G_{i k}$ is the proportion of the small, age-class $k$ populations spawned in season $i$ that grows to a larger class in the next year. We assumed that somatic growth is independent of the parents' body length; therefore,

Table 2. Definitions of parameters used in Eqs. (1) to (10), estimated values, and references used for estimation. See Section A2 in the supplement at www.int-res.com/articles/suppl/m418p179_supp.pdf for the estimation methods. spr: spring, sum: summer, mat. prob.: maturation probability, YOY: young of the year

\begin{tabular}{|c|c|c|c|}
\hline Parameter & Definition & Value & Source $^{a}$ \\
\hline$N_{i j k}$ & $\begin{array}{l}\text { Number of individuals spawned in season } i(i=s p r, \text { sum }) \\
\text { belonging to size class } j(j=S, L \text { for age } \geq 1 \text {, none for age }=0) \\
\text { and age class } k(k=0,1,2+)\end{array}$ & - & - \\
\hline$S_{A}$ & Intrinsic survivability of adults & 0.472 & 1 \\
\hline$E_{D}, E_{L}$ & Survivability against discarding and landing, respectively & $0.369,0.104$ & $2,3,4,5,6$ \\
\hline \multirow[t]{3}{*}{$R_{\text {Lspr }}, R_{\text {Lsum }}$} & Products of sex ratio, clutch size, and maturity of large & Sex ratio: 0.5 & 1 \\
\hline & adults in spring and summer, respectively & Clutch size: 61039 & 7 \\
\hline & & Mat. prob.: $0.75,0.35$ & 4 \\
\hline \multirow{3}{*}{$R_{\text {Sspr }}, R_{\text {Ssum }}$} & Products of sex ratio, clutch size, and maturity of small & Sex ratio: 0.5 & 1 \\
\hline & adults in spring and summer, respectively & Clutch size: 23393 & 7 \\
\hline & & Mat. prob.: $0.21,0.57$ & 4 \\
\hline$g_{0}$ & $\begin{array}{l}\text { Proportion of spring-spawned YOY that grow to a larger size } \\
\text { at the summer spawning in the year following birth }\end{array}$ & 0.558 & $2,3,4,5,6$ \\
\hline$G_{i \mathrm{k}}$ & $\begin{array}{l}\text { Proportions of age- } k(k=0,1,2+) \text { individuals in year } t \text {, spawned } \\
\text { in season } i(i=s p r, \text { sum }) \text { that grow to a larger size in year } t+1\end{array}$ & $\begin{array}{l}\text { spr0: } 0.777, \operatorname{sum} 0: 0.662 \\
\text { spr 1: } 0.803, \operatorname{sum} 1: 0.811 \\
\text { spr } 2+: 0.727, \operatorname{sum} 2+: 0.750\end{array}$ & $2,3,4,5,6$ \\
\hline$S_{\text {sum }}$ & $\begin{array}{l}\text { Product of hatchability, larval survivability, and settlement } \\
\text { success for the summer cohort }\end{array}$ & 0.00042 & - \\
\hline$S_{s p r}$ & $\begin{array}{l}\text { Product of hatchability, larval survivability, and settlement } \\
\text { success for the spring cohort }\end{array}$ & $0.1 S_{\text {sum }}$ & 8 \\
\hline
\end{tabular}


(a)

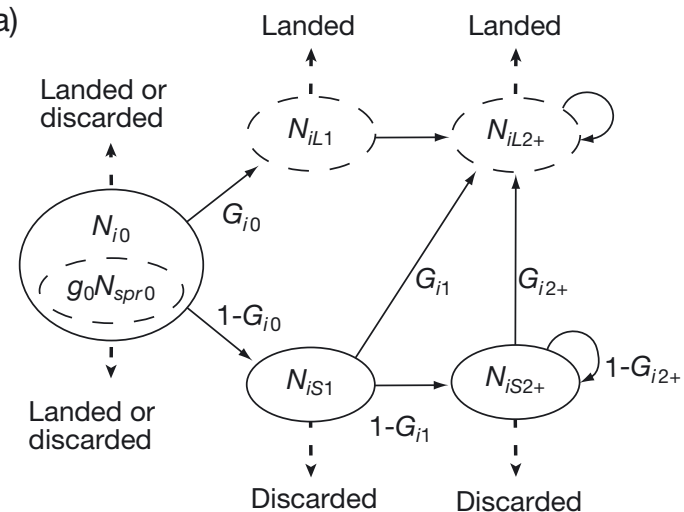

(b)
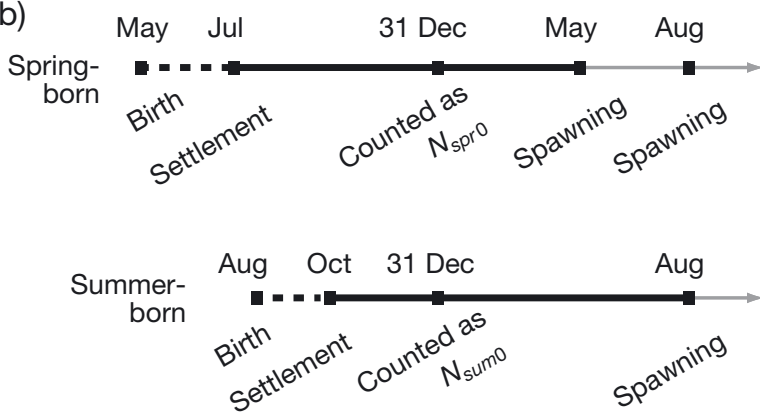

Fig. 2. Oratosquilla oratoria. (a) Stage transition described in Eqs. (1) to (10). Populations spawned in season $i(i=s p r$ or sum; i.e. spring or summer) in dashed circles have a peak spawning season in spring, whereas others have a peak spawning season in summer. Solid arrows indicate transitions between stages associated with intrinsic survival $\left(S_{\text {spr }}, S_{\text {sum }}\right.$, or $S_{A}$ ) and also somatic growth when $G_{i 0}, G_{i 1}$, or $G_{i 2+}$ is included ( $i=$ spr or sum). Dotted arrows show outflows due to fishing (discarding or landing). (b) Life history of spring- and summer-born individuals assumed in the model, Eqs. (1) to (10). Parameters of survivability used in Eqs. (1) to (10) change with life-history stage from (1) $S_{s p r}$ or $S_{\text {sum }}$ depending on the season of birth during the larval period (dashed line) to (2) $S_{A}$ times $E_{D}$ after settlement until they reach about $1 \mathrm{yr}$ of age (black solid line) and then to (3) $S_{A}$ times $E_{L}$ or $E_{D}$ depending on body length (gray line). See Table 2 for parameter explanations

spring- and summer-spawned populations have the same somatic growth rate. The dynamic equation for the oldest, large size class is

$$
\begin{aligned}
N_{i L 2+, t+1}= & \left(N_{i L 1, t}+N_{i L 2+, t}\right) E_{L} S_{A}+ \\
& \left(N_{i S 1, t} G_{i 1}+N_{i S 2+, t} G_{i 2+}\right) E_{D}^{5 / 12} E_{L}^{7 / 12} S_{A}
\end{aligned}
$$

For simplicity, we assumed that adults grow larger in June, i.e. after the spring spawn and before the summer spawn, because of slow somatic growth from January to May (Kodama et al. 2005). Age 1 and older adults have different probabilities to grow to a larger class, $G_{i 1}$ or $G_{i 2+}$. Therefore, in the model, all $N_{i S 1}$ and $N_{i S 2+}$ in year $t$ are subject to mortality due to discarding until June, and those that grow to a larger class $\left(N_{i S 1, t}\right.$ $\left.G_{i 1}+\mathrm{N}_{i S 2+, t} G_{i 2+}\right)$ are afterwards subject to mortality due to landing. $E_{D}$ can be expressed as $\mathrm{e}^{-F}$ with a constant annual mortality, $F$. Thus, the survivability for 5 mo (January to May) is $\mathrm{e}^{-5}{ }_{12}^{F}=E_{D}{ }^{5 / 12}$. To express survivability against landing for the rest of the year, i.e. 7 mo, $E_{L}$ is raised to the power of $7 / 12$.

The population size of age-1, small adults in year $t+1$ is calculated from the YOY that do not grow larger:

$$
N_{i S 1, t+1}=N_{i 0, t}\left(1-G_{i 0}\right) E_{D} S_{A}
$$

again with $i=s p r$ or sum. We assumed all YOY have the potential to be captured by fishing (see Section A2 in the supplement at www.int-res.com/articles/suppl/ m418p179_supp.pdf for reasons).

The population size $N_{i L 1}$ in year $t+1$ is calculated as

and

$$
\begin{aligned}
N_{s p r L 1, t+1} & =N_{s p r 0, t} G_{s p r 0} E_{D}^{5 / 12} E_{L}^{7 / 12} S_{A} \\
N_{\text {sumL } 1, t+1} & =N_{\text {sum } 0, t} G_{\text {sum } 0} E_{D}^{8 / 12} E_{L}^{4 / 12} S_{A}
\end{aligned}
$$

We assume that all YOY will remain smaller than the landing size until 1 yr after birth because previous data have indicated that $95 \%$ of YOY were $<10 \mathrm{~cm}$ when the majority reached $1 \mathrm{yr}$ of age (Kodama et al. 2005). YOY that grow to a large class will afterward be landed when caught. Therefore, all $N_{s p r 0}$ will be discarded until 5 mo after the population count at the end of year $t$ (see Fig. 2b). $E_{D}$ and $E_{L}$ in Eq. (4a) are thus raised to the power of $5 / 12$ and $7 / 12$, respectively. Because $N_{\text {sumo }}$ starts to grow large beginning in September (i.e. $1 \mathrm{yr}$ after birth) in the model, $E_{D}$ and $E_{L}$ are raised to the power of $8 / 12$ and $4 / 12$ in Eq. ( $4 \mathrm{~b})$, respectively.

The number of eggs spawned in the spring by large and small females in year $t+1, E g g_{L s p r, t+1}$ and $E g g_{S s p r, t+1}$, respectively, are

$$
\begin{aligned}
& E g g_{L s p r, t+1}=\left(N_{\text {sprL1,t }}+N_{\text {sumL1,t }}+\right. \\
& \left.N_{\text {sprL2+, } t}+N_{\text {sumL2+, } t}\right) E_{L}^{4 / 12} S_{A}^{4 / 12} R_{L s p r} \\
& E g g_{S s p r, t+1}=\left(N_{s p r 0, t}+N_{s p r S 1, t}+N_{s u m S 1, t}+\right. \\
& \left.N_{\text {sprS2+, } t}+N_{\text {sumS } 2+, t}\right) E_{D}^{4 / 12} S_{A}^{4 / 12} R_{\text {Sspr }}
\end{aligned}
$$

The parents of spring-spawned YOY are large and small individuals that survived until the spawning season, which is approximately 4 mo. Therefore, in Eqs. (5) \& (6), $S_{A}, E_{L}$, and $E_{D}$ are each raised to the power of $4 / 12$. We set $R_{L s p r}$ and $R_{S s p r}$ as the number of eggs per large and small individual multiplied by the proportions of mature females in the spring, respectively. $R_{\text {Lsum }}$ and $R_{\text {Ssum }}$ are the respective equivalent parameters for a summer spawning. We use the parameters $R_{\text {Lspr }} R_{\text {Sspr }}, R_{\text {Lsum }}$ and $R_{\text {Ssum }}$ regardless of age because maturity does not significantly differ among ages (K. Kodama unpubl. data), and clutch size de- 
pends on body length rather than on age. We assumed no spring spawning in year $t+1$ for YOY born in the summer of year $t$ because most of these individuals are less than the minimum size at maturation in the spring ( $85 \%$ were $<7 \mathrm{~cm}$, and the remainder were $7-8 \mathrm{~cm}$ in March; Kodama et al. 2006d). These individuals join spawning in the summer in year $t+1$ when they reach almost $1 \mathrm{yr}$ of age, although we assume that they remain small ( $95 \%$ were $<10 \mathrm{~cm}$ in August; Kodama et al. 2005). In contrast, spring-spawned YOY born in year $t$ have grown for almost a year and could be reproductively mature in the spring of year $t+1$. We assume that they become large at the summer spawning in year $t+1$ with a probability of $g_{0}$. Therefore, the numbers of eggs spawned by large and small females, respectively, in the summer are:

$$
\begin{aligned}
& E g g_{\text {Lsum }, t+1}=\left(N_{s p r 0, t} g_{0}+N_{s p r S 1, t} G_{s p r 1}+\right. \\
& \left.N_{\text {sumS1 }, t} G_{\text {sum } 1}+N_{\text {sprS2+, }} G_{\text {spr } 2}+N_{\text {sumS2+, }} G_{\text {sum } 2}\right) \\
& E_{D}^{5}{ }^{5 / 12} E_{L}^{2} / 12 S_{A}^{7 / 12} R_{L s u m}+\left(N_{s p r L 1, t}+N_{\text {sumL } 1, t}+N_{\text {sprL2 }+, t}+\right. \\
& \left.N_{\text {sumL } 2+, t}\right) E_{L}^{7 / 12} S_{A}^{7 / 12} R_{\text {Lsum }}
\end{aligned}
$$

and

$$
\begin{aligned}
& \operatorname{Egg}_{\text {Ssum }, t+1}=\left[N_{\text {spr } 0, t}\left(1-g_{0}\right)+N_{\text {sum } 0, t}+\right. \\
& N_{\text {sprS1,t }}\left(1-G_{\text {spr } 1}\right)+N_{\text {sumS } 1, t}\left(1-G_{\text {sum } 1}\right)+ \\
& \left.N_{\text {sprS2+, }}\left(1-G_{\text {spr } 2}\right)+N_{\text {sumS } 2+, t}\left(1-G_{\text {sum } 2}\right)\right] \\
& E_{D}{ }^{71} S_{A}^{7}{ }^{71} R_{\text {Ssum }}
\end{aligned}
$$

Note that the parents of the summer cohort are those that survived 7 mo until spawning.

Egg hatchability, survivability during the 2 mo larval stage, and the probability of successful settlement for the spring cohort is $S_{s p r}$. Here, successful settlement refers to survival until the start of benthic life in the appropriate environment. In other words, $S_{s p r}$ is survivability at an early life stage before the intrinsic survivability changes to $S_{A}$. Thus, recruitment from eggs spawned by large and small females is calculated as $E g g_{L s p r, t+1} S_{s p r}$ and $E g g_{S s p r, t+1} S_{s p r r}$ respectively. The population size of $N_{s p r 0}$ can be calculated as recruitment multiplied by survivability as an adult after settlement until the next population count (i.e. 6 mo) and by survivability against discarding for 4 mo after individuals reach the size that can be captured by the fishing net (since 2 mo after settlement). Therefore, we have

$$
N_{s p r 0, t+1}=\left(E g g_{L s p r, t+1}+E g g_{S s p r, t+1}\right) S_{s p r} S_{A}^{6 / 12} E_{D}^{4 / 12}
$$

Similarly, the dynamics of the summer cohort are:

$N_{\text {sum } 0, t+1}=\left(E_{\text {g }} g_{\text {Lsum }, t+1}+E g g_{\text {Ssum }, t+1}\right) S_{\text {sum }} S_{A}{ }^{3 / 12} E_{D}^{1 / 12}$

Larval survivability and the probability of settlement are assumed to be substantially higher in the summer than in the spring (Shimizu 2000, Kodama et al. 2006a; see Table 2). The number of landings is assumed to be proportional to the stock size (see Section A3 in the supplement for detailed calculations). The population dynamics, Eqs. (1) to (10), can also be described by a matrix model:

$$
\mathbf{n}(t+1)=\mathbf{A} \mathbf{n}(t)
$$

where $\mathbf{n}$ is a vertical vector with all populations of $N_{i j k}$ ( $i=\operatorname{spr}_{1} \operatorname{sum}_{i} j=S, L$ or none; $k=0,1,2+$ ) and $\mathbf{A}$ is the population projection matrix. Full description of $\mathbf{A}$ is provided in Section A1 in the supplement to avoid a lengthy description in the text. We use the dominant eigenvalue, $\lambda$, of matrix $\mathbf{A}$ as the measure of the population growth rate (Caswell 2001).

We used published data on Oratosquilla oratoria in Tokyo Bay to estimate the parameter values, as described in detail in Section A2 in the supplement. However, because no data were available for the probabilities of hatching and settlement, we estimated $S_{\text {sum }}$ using the least-squares method to fit LPUE calculated in the simulation to LPUE data for the period of 1991 to 2003. Average larval survivability in the summer and spring for 1992 to 1998 were 0.01 and 0.001, respectively (Shimizu 2000). Therefore, we set $S_{s p r}=$ $0.1 S_{\text {sum. }}$.

The stock size in 2003 (i.e. $N_{s p r L 1,2003}+N_{s p r L 2+, 2003}+$ $N_{\text {sumL1,2003 }}+N_{\text {sumL2+,2003) }}$ was estimated from landing data (see Section A3 in the supplement for details of the estimation method). Other population sizes were estimated from the ratio of the number of small individuals to the number of large individuals (i.e. discarded to landed, 0.95) obtained from an age-size distribution calculated from data provided by Kodama et al. (2005, 2006d; see also Section A3 in the supplement for calculation details). We substituted these population sizes into Eqs. (1) to (10), ran a simulation for $100 \mathrm{yr}$, and obtained a stable population size distribution. This ratio and the estimated stock size in 2003 provided the population sizes in 2003 that were used in our calculations.

Next, to quantify the impact of the spawning shift on Oratosquilla oratoria population dynamics, we calculated recruitment of a hypothetical population that had the same maturity as in the 1980 s, i.e. before the spawning shift occurred, and compared it to the estimate of current, real recruitment calculated as described above. We used the proportions of mature females observed in 1987 (large individuals in spring = 0.643 , large individuals in summer $=0.263$, small individuals in spring $=0.080$, and in summer $=0.085$; data from Ohtomi \& Shimizu 1988), instead of the estimated values for current maturity, to obtain $R_{L s p r} R_{S s p r} R_{L s u m}$ and $R_{\text {Ssum }}$. Other parameter values, age- and sizestructure, and population sizes for each age and size 
class were the same as those estimated for the present population because no data were available to estimate these parameters for the 1980s. Therefore, the intention of this calculation was not to describe reproduction and recruitment that occurred in the 1980s, but to estimate values for a hypothetical population.

Fishery mortalities that maintain the population. To determine how the population growth rate changed in response to fishing mortalities from discarding and landing, we described $\lambda$ as a function of either $E_{D}$ or $E_{L}$, while other parameters remained fixed to the estimated values (Table 2). To compare minimum $E_{D}$ and $E_{L}$ values for the present population to persist, we searched for values that satisfied $\lambda \geq 1$, which indicated positive population growth (Caswell 2001).

Sensitivity analysis. We evaluated the effects of parameters on population dynamics in our model as the elasticity of the population growth rate $\lambda$ to each parameter $x$,

$$
\mathrm{d} \lambda / \delta x=\frac{x}{\lambda} \sum_{i, j} \frac{\partial \lambda}{\partial a_{i j}} \frac{\partial a_{i j}}{\partial x}
$$

where $a_{i j}$ denotes the entry in the $i$ th row and the $j$ th column of matrix A. Elasticity enables us to compare the responses of $\lambda$ to perturbations in parameters that have different scales, such as survival and fertility (Caswell 2001). A parameter with a relatively large elasticity has a larger influence on the model output.

We used Mathematica 7.0 (Wolfram Research) for all simulations, analyses, and calculations.

\section{RESULTS}

\section{Contributions of seasonal cohorts to the population}

Estimated parameter values are shown in Table 2. The stock size in 2003 was estimated as 10547716 individuals. The initial numbers of individuals were therefore $N_{\text {spr } 0,0}=269770, \quad N_{\text {sum } 0,0}=17188804$, $N_{\text {sprS1, } 0}=23725, N_{\text {sprL1,0 }}=12806, N_{\text {sumS } 1,0}=1869433$, $N_{\text {sumL } 1,0}=886534, N_{\text {sprS } 2+, 0}=1763, N_{\text {sprL } 2+, 0}=2230$, $N_{\text {sumS2 }+, 0}=147658$ and $N_{\text {sumL2+, }}=165324$. The growth rate $\lambda$ with the estimated parameter values was 0.91 .

Both the number of eggs and recruitment in the current situation were higher for the summer cohort than for the spring cohort (Fig. 3); values were higher by 4.1 and 41 times (because we assumed $S_{s p r}=0.1 S_{\text {sum }}$ ), respectively.

With the same maturation probabilities as determined in the 1980s, the hypothetical population growth rate $\lambda$ decreased to 0.40 . The number of eggs and total recruitment in this hypothetical population were $34 \%$ and $25 \%$ of the current situation, respectively (Fig. 3).
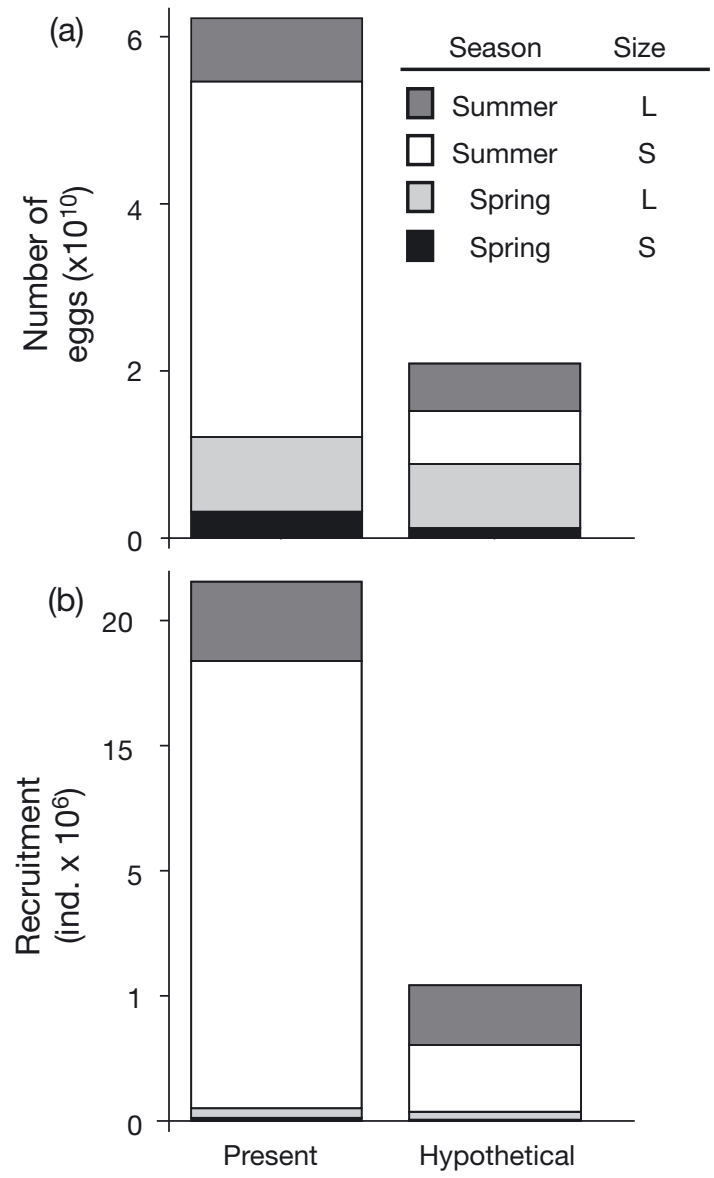

Fig. 3. Oratosquilla oratoria. (a) Numbers of eggs and (b) recruitment estimates for the current and hypothetical populations with maturation frequencies from the 1980s, shown for each seasonal cohort (spring or summer) spawned by each size of females (small or large)

\section{Fishery mortalities that maintain the population}

The population growth rate $\lambda$ increased monotonically with both $E_{D}$ and $E_{L}$ (Fig. 4). The inequality $\lambda \geq 1$ was satisfied when $E_{D}=0.428$ or $E_{L}=0.260$. These values were 1.2 and 2.5 times larger than the originally estimated values (Table 1), respectively.

\section{Sensitivity analysis}

Several survivability parameters $\left(S_{A}, S_{\text {sum }}\right.$ and $\left.E_{D}\right)$ and 1 summer reproduction parameter $\left(R_{\text {Ssum }}\right)$ showed the largest elasticity, followed by parameters for the reproduction and survival of large individuals $\left(R_{\text {Lsum }}\right.$ and $E_{L i}$ Fig. 5). With all 6 of these parameters, elasticity values were positive, indicating that the population growth rate decreased when the parameter values decreased. Only the parameters of the somatic growth of YOY, $G_{s p r 0}$, and $G_{s u m 0}$ showed negative elasticity. 


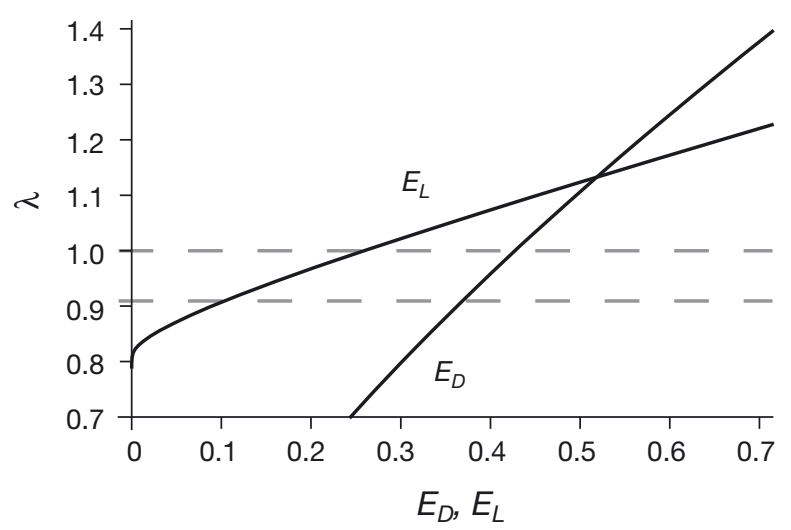

Fig. 4. Population growth rate $(\lambda)$ as a function of survivability against discarding $\left(E_{D}\right)$ and landing $\left(E_{L}\right)$ (solid lines). The dashed lines describe $\lambda=0.91$ (estimated value for the present population) and $\lambda=1$

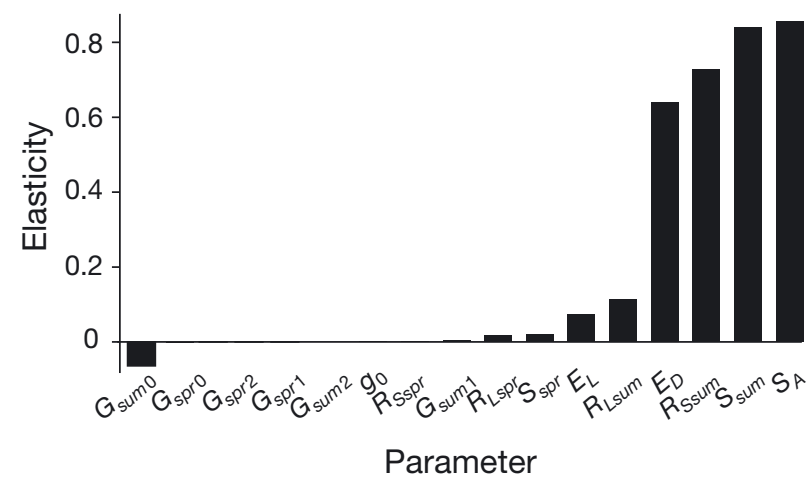

Fig. 5. Elasticity of the population growth rate $(\lambda)$ in response to each parameter. See Table 2 for parameter notations

\section{DISCUSSION}

Our model suggested that both the additional spawning peak in the summer and the increase in the maturity rate for smaller females increased the population growth rate of Oratosquilla oratoria. The summer cohort accounted for $98 \%$ of the current total recruitment. Furthermore, the estimated number of eggs spawned during spring in the current population was smaller than in the summer (Fig. 3a). This result suggests that the major spawning currently takes place in the summer, whereas primary spawning used to occur in the spring, at least during the 1950s to 1980 s (Shimizu 2002, Kodama et al. 2004, 2006c). Our calculation also showed that individuals currently derived from small spawners constituted $84 \%$ of the total recruitment. The lower recruitment estimate for a hypothetical population with the same maturation probabilities as observed in the 1980s (Fig. 3b) produced a smaller population growth rate than the current spawning pattern. Thus, our model suggests that the shift in the spawning pattern was effective for maintaining the population.

The causes of seasonal differences in Oratosquilla oratoria survival remain unclear. Settlement inhibition due to seasonal hypoxia (when dissolved oxygen reaches levels at which most animals suffocate; $<2 \mathrm{mg}$ $\mathrm{l}^{-1}$; Diaz 2001) is the only explanation provided so far. In the bottom waters at the head of Tokyo Bay, hypoxic conditions occur annually in the summer (Ando et al. 2005), causing high faunal mortality (Kodama et al. 2010). The disproportionate survival observed for 1 of the 2 seasonal spawnings in a benthic fish population in Tokyo Bay (dragonet Callionymus valenciennei) also might have been caused by seasonal hypoxia (Ikejima \& Shimizu 1999). Detrimental effects of seasonal hypoxia have been suggested for $O$. oratoria populations in other seas of Japan (Hiuchi-nada, Kawamura et al. 1997; Ise Bay, Narita et al. 2007), as well as for other organisms around the world (reviewed by Diaz 2001). To our knowledge, no prior study has reported seasonal shifts in spawning due to hypoxia. Comparative analysis among the life histories of populations affected by hypoxia may provide insight into why the shift in spawning seasonality has been uniquely observed in this population of $O$. oratoria.

Regardless of the direct cause of low survival, our model describes disproportionate survival between seasons. The comparative analysis of populations in other seasonally severe environments will enrich our understanding of the adaptiveness of spawning seasonality. Crustacean populations often show bimodal peaks of spawning season within a year that have equally efficient contributions to recruitment, with the body-length structure of the spawning population differing between peaks (e.g. Krygier \& Horton 1975, Crocos \& van der Velde 1995, Ohtomi \& Matsuoka 1998), suggesting that multiplicity can be adaptive. For example, the bimodal spawning season of the American lobster Homarus americanus may help spread larval production through time to disperse risk in an uncertain, temporally variable environment (Gendron \& Ouellet 2009). In contrast, 1 of the 2 seasonal spawning peaks of banana prawn Penaeus merguiensis in the southeastern Gulf of Carpentaria, Australia, provides significantly lower recruitment than the other peak, partly due to poor advection for larvae into the favorable habitat (Dall et al. 1990 and references therein). In P. merguiensis, the major spawning peak is the one which provides lower recruitment, unlike the case of Oratosquilla oratoria in Tokyo Bay as our model suggested. Higher survival at larval and/or juvenile stages may be the major selective force for the appearance of the new, dominant spawning peak in $O$. oratoria, but not in $P$. merguiensis. Spawning time of crustaceans also depends on the spawners' biological 
constraints, such as molting, gonadal growth rate, and size at maturation, which is often correlated with environmental conditions (Ware \& Tanasichuk 1989, Dall et al. 1990). General understanding of the relationship between spawning season and seasonal egg wasting is needed to explain the adaptiveness of spawning seasonality.

In crustaceans with indeterminate growth, such as Oratosquilla oratoria, energy resources can be allocated to both reproduction and nonreproductive development (including somatic growth and molting; Ouellet \& Plante 2004). Therefore, starting investment to reproduction and becoming mature at a small size may result in less somatic growth. In our model, reductions in $G_{i k}$ or its dependence on the parents' body length correspond to this assumption, and both result in decreases in the number of large individuals (see Section B1 in the supplement at www.int-res.com/articles/ suppl/m417p179_supp.pdf for details). In reality, LPUE data show that the number of large individuals has declined (Fig. 1), although this pattern may reflect the specific exploitation of large individuals and not their absence from the population. Reductions in size at maturation have been suggested to be induced by high mortality on large individuals due to size-selective fishing in various other organisms (reviewed by Trippel 1995, Law 2000, Kuparinen \& Merila 2007). We have shown here that the immediate solution for population recovery is to protect small spawners, but managing the harvesting of large individuals may be able to efficiently avoid further reductions in size at maturation (Conover 2007) if size-selective fishing has induced an early-age of maturation in $O$. oratoria.

The population growth rate $\lambda$ responds quicker to changes in $E_{D}$ than to changes in $E_{L}$ (Fig. 4). However, we should note that the population dynamics of Eqs. (1) to (10) are based on an assumption of $0 \%$ escape probability for individuals $>5 \mathrm{~cm}$, which could overestimate mortality among small individuals $\left(E_{D}\right)$ and hence overestimate the model sensitivity to $E_{D}$. Nevertheless, given the large difference in elasticity to $E_{D}$ and $E_{L}$ (Figs. $4 \& 5$ ), $E_{D}$ may have a larger impact on population dynamics than does $E_{L}$. Therefore, devoting greater effort toward managing fishing mortality on small compared to large individuals may provide a more efficient means for population recovery. To this end, Ishii et al. (2001) devised a fishing net with a larger mesh size and a different mesh shape (from diamond- to square-shaped) compared with the nets originally used for fisheries; the new design effectively reduced the probability of catching small individuals (Ishii et al. 2001, Ogawa et al. 2001). Using this net, $E_{D}$ and $E_{L}$ become body length-dependent. The model with such change of parameters is shown in Section B2 in the supplement. The model predicted that $\lambda$ would greatly increase (Fig. S3 in the supplement at www.intres.com/articles/suppl/m418p179_supp.pdf). Because further discussion on fishery management is beyond our purpose, we limit ourselves here to suggest applying a framework which combines biology, economics, and decision-making processes, as elaborated by Punt et al. (2010).

Some of the parameters to which the model was highly sensitive must be estimated more accurately than others (Akçakaya et al. 1999). $E_{D}$ was estimated directly from reliable field observations (Kitahara \& Maki 1997; see Section A2 in Supplement 1), although the data represent only a recent period with a low stock, and the discarding rate may depend on stock size. The exploitation of Oratosquilla oratoria for more than 200 yr has made it extremely difficult to estimate survivability without a fishery, $S_{A}$ (Nakata 1990). Because no data were available for $S_{A}, S_{s p r}$, or $S_{\text {sum }}$, more field observations combined with laboratory breeding are necessary. The estimation of the parameters $S_{A}, E_{L}, E_{D}$ and $G_{i k}$ depends on the same LPUE data and age and size distribution data obtained from limited periods. Because age and size distributions may change through time, constant observations such as annual sampling are required for accurate estimates.

Our model incorporates several assumptions concerning the life history and population dynamics of Oratosquilla oratoria. Although these assumptions were based on data, one could also expect alternative models. First, the reproductive maturation probability of summer-spawned individuals at the first potential spawning (i.e. the summer $1 \mathrm{yr}$ after birth) is higher than that of spring-spawned individuals (i.e. in the spring $1 \mathrm{yr}$ after birth) because of the lower maturity in the spring among small individuals (spring/summer = 0.37; Kodama et al. 2006c), which was independent of age (K. Kodama unpubl. data). This difference in maturation could have reduced recruitment from springspawned individuals. However, the seasonal difference in the probability of survival until adulthood $\left(S_{\text {spr }} / S_{\text {sum }}=0.1\right)$ was larger than the difference in the reproductive parameters. The increase of population growth rate from the original estimate was smaller when we used the same reproductive parameter for spring- and summer-spawned individuals at the first potential spawning (i.e. use $R_{\text {Ssum }}$ instead of $R_{S s p r}$ for only $N_{s p r 0}$ in Eq. 6) than when $S_{s p r}$ was increased to the same level as $S_{\text {sum }}$ (Fig. S3 in the supplement). Thus, lower survival of spring-spawned juveniles more strongly affects population dynamics than does a lower maturation rate.

Second, the model assumed constant survivability $\left(S_{A}, E_{L}\right.$ and $\left.E_{D}\right)$ throughout an entire year and an entire lifetime. Data are not yet available to discuss seasonality, age-dependence, or temporal variation of 
survivability, other than the seasonal mortality of discarded individuals; the suggested mortality was higher in July to August than in other months (Kitahara \& Maki 1997). A converted model with this seasonal discarding mortality is shown in Section B3 in the supplement. The population growth rate $\lambda$ slightly increased (by 0.032 ) from the original model, and $\lambda$ responded more quickly to the change of $E_{D}$ in months other than July and August (Fig. S5 in the supplement). A hypothetical model with age-dependent survivability is described in Section B4 in the supplement. The elasticity of $\lambda$ of this model was larger in response to the survivability of younger individuals (Fig. S6 in the supplement). The intrinsic survivability can also vary across time due to environmental fluctuations. The large elasticity of $\lambda$ in response to $S_{A}$ (Fig. 5) suggests that population dynamics would also fluctuate with unstable $S_{A}$. In fact, when we assumed that the annual variation of $S_{A}$ was the same as that of LPUE from 1991 to 2003, $\lambda$ ranged from below the original estimate to above 1 (details are shown in Section B5 in the supplement). Thus, our estimate of population dynamics could have been biased by the assumption of constant survival. More field data on mortality would clearly improve the estimation. In contrast, the constancy of survivability did not alter our conclusion of greater reproduction by small spawners in the summer (Fig. S3 in the supplement).

Acknowledgements. We thank I. Aoki, T. Shimizu, Y. Tajima, T. Suzuki, S. Nagayama, the Kanagawa Prefectural Fisheries Technology Center, and the Chiba Prefectural Fisheries Research Center for providing raw data, and M. Fujiwara, M.L. Knope, K. Morita, and anonymous reviewers for comments.

\section{LITERATURE CITED}

Akçakaya HR, Burgman MA, Ginzburg LR (1999) Applied population ecology: principles and computer exercises using RAMAS EcoLab 2.0. Sinauer Associates, Sunderland, MA

Ando H, Kashiwagi N, Ninomiya K, Ogura H, Kawai T (2005) Changes in the state of water pollution in Tokyo Bay since 1980. Trend analysis of water quality using monitoring data obtained by local governments. Annual Report of the Tokyo Metropolitan Research Institute for Environmental Protection, Tokyo Metropolitan Research Institute for Environmental Protection, Tokyo

Caswell H (2001) Matrix population models: construction, analysis, and interpretation, 2nd edn. Sinauer Associates, Sunderland, MA

> Conover DO (2007) Nets versus nature. Nature 450:179-180

- Crocos PJ, van der Velde TD (1995) Seasonal, spatial and interannual variability in the reproductive dynamics of the grooved tiger prawn Penaeus semisulcatus in Albatross Bay, Gulf of Carpentaria, Australia: the concept of effective spawning. Mar Biol 122:557-570

Dall W, Hill BJ, Rothlisberg PC, Staples DJ (1990) The biol- ogy of the Penaeidae. In: Blaxter JHS, Southward AJ (eds) Advances in marine biology, Vol 27. Academic Press, London

> Diaz RJ (2001) Overview of hypoxia around the world. J Environ Qual 30:275-281

> Gendron L, Ouellet P (2009) Egg development trajectories of early and late-spawner lobsters (Homarus americanus) in the Magdalen Islands, Québec. J Crustac Biol 29:356-363

> Hare JA, Cowen RK (1993) Ecological and evolutionary implications of the larval transport and reproductive strategy of bluefish Pomatomus saltatrix. Mar Ecol Prog Ser 98:1-16

Hutchings JA, Myers RA (1993) Effect of age on the seasonality of maturation and spawning of Atlantic cod, Gadus morhua, in the Northwest Atlantic. Can J Fish Aquat Sci 50:2468-2474

> Ikejima K, Shimizu M (1999) Disappearance of a spring cohort in a population of the dragonet, Repomucenus valenciennei, with spring and autumn spawning peaks in Tokyo Bay, Japan. Ichthyol Res 46:331-339

Ishii H, Ogawa S, Egawa K (2001) Development of small beam trawl based on rational resource management for mantis shrimp (Oratosquilla oratoria) in Tokyo Bay. I. Development of codend trawl notice of mesh selectivity. Bull Kanagawa Pref Fish Res Inst 6:81-88

Kawamura Y, Hamano T, Kagawa T (1997) Distribution of larvae and juveniles of the Japanese mantis shrimp Oratosquilla oratorio (De Haan, 1844) (Stomatopoda) in the Sea of Hiuchi-Nada, Japan. Crustac Res 26:75-82

Kitahara T, Maki S (1997) Individual quota and discarded fish - mantis shrimp in Tokyo Bay as an example. Gekkan Kaiyo 29:333-336

> Kodama K, Shimizu T, Yamakawa T, Aoki I (2004) Reproductive biology of the female Japanese mantis shrimp Oratosquilla oratoria (Stomatopoda) in relation to changes in the seasonal pattern of larval occurrence in Tokyo Bay, Japan. Fish Sci 70:734-745

Kodama K, Yamakawa T, Shimizu T, Aoki I (2005) Age estimation of the wild population of Japanese mantis shrimp Oratosquilla oratoria (Crustacea: Stomatopoda) in Tokyo Bay, Japan, using lipofuscin as an age marker. Fish Sci 71:141-150

Kodama K, Horiguchi T, Kume G, Nagayama S, Shimizu T, Shiraishi H, Morita M, Shimizu M (2006a) Effects of hypoxia on early life history of the stomatopod Oratosquilla oratoria in a coastal sea. Mar Ecol Prog Ser 324: 197-206

Kodama K, Kume G, Shiraishi H, Morita M, Horiguchi T (2006b) Relationship between body length, processedmeat length and seasonal change in net processed-meat yield of Japanese mantis shrimp (Oratosquilla oratoria) in Tokyo Bay. Fish Sci 72:804-810

> Kodama K, Shimizu T, Yamakawa T, Aoki I (2006c) Changes in reproductive patterns in relation to decline in stock abundance of the Japanese mantis shrimp, Oratosquilla oratoria, in Tokyo Bay. Fish Sci 72:568-577

Kodama K, Shiraishi H, Morita M, Horiguchi T (2006d) Verification of lipofuscin-based crustacean ageing: seasonality of lipofuscin accumulation in the stomatopod Oratosquilla oratoria in relation to water temperature. Mar Biol 150: $131-140$

Kodama K, Oyama M, Lee JH, Akaba Y, Tajima Y, Shimizu T, Shiraishi H, Horiguchi T (2009) Interannual variation in quantitative relationships among egg production and densities of larvae and juveniles of the Japanese mantis shrimp Oratosquilla oratoria in Tokyo Bay, Japan. Fish Sci 75:875-886

Kodama K, Oyama M, Kume G, Serizawa S, Shiraishi H, Shi- 
bata Y, Shimizu M, Horiguchi T (2010) Impaired megabenthic community structure caused by summer hypoxia in a eutrophic coastal bay. Ecotoxicology 19:479-492

Krygier EE, Horton H (1975) Distribution, reproduction, and growth of Crangon nigricauda and Crangon franciscorum in Yaquina Bay, Oregon. Northwest Sci 49:216-240

Kubo I, Hori S, Kumemura M, Naganawa M, Soedjono J (1959) A biological study on a Japanese edible mantis shrimp, Squilla oratoria de Haan. J Tokyo Univ Fish 45:1-25

Kuparinen A, Merila J (2007) Detecting and managing fisheries-induced evolution. Trends Ecol Evol 22:652-659

Law R (2000) Fishing, selection, and phenotypic evolution. ICES J Mar Sci 57:659-668

Lipcius RN (1985) Size-dependent reproduction and molting in spiny lobsters and other long-lived decapods. In: Wenner AM (ed) Crustacean growth: factors in adult growth. Balkema, Rotterdam, p 129-148

Nakata N (1986) Larval distribution of Oratosquilla oratoria (de Haan) in Tokyo Bay. Bull Kanagawa Pref Fish Exp Stn $7: 17-22$

Nakata N (1990) The assessment of stock and stock condition on the Japanese mantis shrimp Oratosquilla oratoria (de Haan) in Tokyo Bay. Bull Kanagawa Pref Fish Exp Stn 11: $17-25$

Narita T, Ganmanee M, Sekiguchi H (2007) Population dynamics of mantis shrimp Oratosquilla oratoria in Ise Bay, central Japan. Bull Jpn Soc Sci Fish 73:18-31

Ogawa S, Ishii H, Egawa K (2001) Development of small beam trawl based on rational resource management for mantis shrimp (Oratosquilla oratoria) in Tokyo Bay. II. The influence that resources management type fishing gear exerts on the operation. Bull Kanagawa Pref Fish Res Inst 6:89-96

Ohtomi J, Matsuoka T (1998) Reproduction and growth of jack-knife shrimp, Haliporoides sibogae, off southwestern Kyushu, Japan. Fish Res 38:271-281

Ohtomi J, Shimizu M (1988) Growth after recruitment com-

Editorial responsibility: Hans Heinrich Janssen,

Oldendorf/Luhe, Germany pletion and life-span of the Japanese mantis shrimp Oratosquilla oratoria in Tokyo Bay. Bull Jpn Soc Sci Fish 54:1935-1940

Ohtomi J, Shimizu M (1996) Market size category composition and stock assessment of the Japanese mantis shrimp Oratosquilla oratoria in Tokyo Bay. Bull Jpn Soc Sci Fish 62:32-39

Ohtomi J, Shimizu M, Vergara JAM (1988) Spawning season of the Japanese mantis shrimp Oratosquilla oratoria. Bull Jpn Soc Sci Fish 54:1929-1933

> Ouellet P, Plante F (2004) An investigation of the sources of variability in American lobster (Homarus americanus) eggs and larvae: female size and reproductive status, and interannual and interpopulation comparisons. J Crustac Biol 24:481-495

Pollock DE (1995) Changes in maturation ages and sizes in crustacean and fish populations. S Afr J Mar Sci 15:99-103

Punt AE, Deng RA, Dichmont CM, Kompas $\mathrm{T}$ and others (2010) Integrating size-structured assessment and bioeconomic management advice in Australia's northern prawn fishery. ICES J Mar Sci 67:1785-1801

Shimizu T (2000) On the survival rate at larval stage of Japanese mantis shrimp, Oratosquilla oratoria, in Tokyo Bay. Bull Kanagawa Pref Fish Res Inst 5:55-60

Shimizu T (2002) On the resource of Japanese mantis shrimp Oratosquilla oratoria (de Haan) in Tokyo Bay. I. Summarization on the resource utilization and life history. Bull Kanagawa Pref Fish Res Inst 7:1-10

Shimizu T (2004) On the resource of Japanese mantis shrimp Oratosquilla oratoria (de Haan) in Tokyo Bay. II. Private plan for recovery of resource. Bull Kanagawa Pref Fish Res Inst 9:1-12

Trippel EA (1995) Age at maturity as a stress indicator in fisheries. Bioscience 45:759-771

Ware DM, Tanasichuk RW (1989) Biological basis of maturation and spawning waves in Pacific herring (Clupea harengus pallasi). Can J Fish Aquat Sci 46:1776-1784

Submitted: September 30, 2009; Accepted: September 14, 2010 Proofs received from author(s): November 6, 2010 